\title{
Possibilities for Enhancing Oil Recovery by Hot Water Injection
}

\author{
Popp V. V., Ciuca G., Buiac V. C.
}

Petrom R. A. - ICPT, Romania

Copyright 1896, Steering Committee of the European IOR - Symposium.

This paper was presented at the Qth. European $10 \mathrm{R}$ - Symposium in Vienna, Austria, Moy 15 - 17, 1895

This paper wes celected for presentation by the Steering Committeo, following review of information contained in an abstract

submitted by the author(e). The peper, es presented has not been reviewed by the Steering Committeo.

\begin{abstract}
The paper presents briefly the research and design works for achieving a hot water injection experimental plant. The plant offers possibilities for extension of hot water injection to enhance oil recovery, providing cost reductions related to investments and operation, of about 3 times less as compared to the current facilities used for hot fluids injection, while avoiding at the same time fresh water consumption from natural sources.

The plant will be fed with purified produced water and will be tested in an experimental pattem made up of an injection weil and five output wells, on a reservoir located at a depth of about $750 \mathrm{~m}$.

Laboratory investigations constitute the background for an effective treatment in order to reduce corrosion and scales deposits. and for increasing the efficiency of the process by adding surfactants to the injection water.

The process consists in heating the formation water to I $50^{\circ} \mathrm{C}$, in a closed system, at a pressure of $0.6 \mathrm{MPa}$, and its injection at a pressure up to $10 \mathrm{MPa}$.

The plant is made of transportable skids which facilitate its installation near the injection well and its transfer to other wells following completion of the experiment.

By preliminary thermal calculations it is estimated that the duration of continuous hot waterflooding will be limited to about 2 years, following which the heat losses to the injection well and to the layers adjacent to the productive formation will surpass $70 \%$ of the injected heat.
\end{abstract}

\section{INTRODUCTION}

To enhance oil recovery by thermal method in situ combustion is being applied on 6 reservoirs, located at depths down to $850 \mathrm{~m}$, and steam injection is being applied on 2 reservoirs located at depths down to 300 m. in Romania.
Literature data $[1,2,3,4]$ show that hot water injection is a thermal method that can be applied efficiently following conventional water injection and even after steam injection.

The experience gathered so far regarding purification of reservoir water [5] and regarding the equipment and heating systems $[6,7,8]$ created a background for the investigations carried out in order to achieve an experimental plant for hot water injection (with the plant to be supplied with purified produced water).

The use of these heating equipments and systems in oil dehydration and desalting plants have diminished the heating costs by about 4 times as compared to the previous practice.

The plant will be manufactured and tested on an injection well belonging to an experimental pattern over a reservoir located at a depth of about $750 \mathrm{~m}$, whose main characteristics are shown in Section 2.

Laboratory investigations, presented in Section 3 were meant to treat injection water (3.1) to reduce the corrosion and scaling effect associated with water heating; to determine the characteristics of produced fluids (3.2) and to evaluate the effect of surfactant addition (3.3) to injection water.

By the preliminary mathematical modelling - presented briefly in Section 4 - heat losses in the injection well and the adjacent layers to the productive formation were evaluated, which will surpass $70 \%$ of the heat input to the well after about 2 years of operation.

The process is briefly presented in Section 5 , together with the heating system (5.1) and the flow sheet (5.2.) The plant is to be manufactured on transportable skids which facilitate the assembly /removal and transportation operations in the vicinity of the injection wells.

\section{MAIN RESERVOIR PARAMETERS}

The productive horizon selected for the test is the Șotânga Meotian, which belongs to a structural align- 
ment bearing characterized by an infricate tectonics. being located in an area of diapiric folds. The reservoir rock is made up of sands, marly sands, with marls and gritty marls intercalations. The reservoir is of the stratiform, vaulted type.

The physical parameters of the horizon of interest were estimated based on the available data, on he well surveys, well logs and correlation curves, and the following values were accepted:

- initial reservoir pressure: $6 \mathrm{MPa}$ (853 psi)

- reservoir temperature: $30^{\circ} \mathrm{C}\left(86^{\circ} \mathrm{F}\right)$

- porosity: $25 \%$

- interstitial water saturation: $25 \%$

- average thickness: $5 \mathrm{~m} \mathrm{(16 \textrm {ft } )}$

- absolute permeability: $0,3 \mu^{2}(300 \mathrm{mD})$

- effective oil permeability: $0,1 \mu^{2}(100 \mathrm{mD})$

- dip: 2-12 deg.

A conventional water injection process has been previously applied to this horizon. Solution gas drive and gas cap expansion are specific to this reservoir.

The experimental pattern is made up of wells $79 \mathrm{MP}$, 75 MP. 72 MP. 53 MP, 63 MP which make up the output cluster, and of well $74 \mathrm{MP}$, which will be an injector (Fig. I)

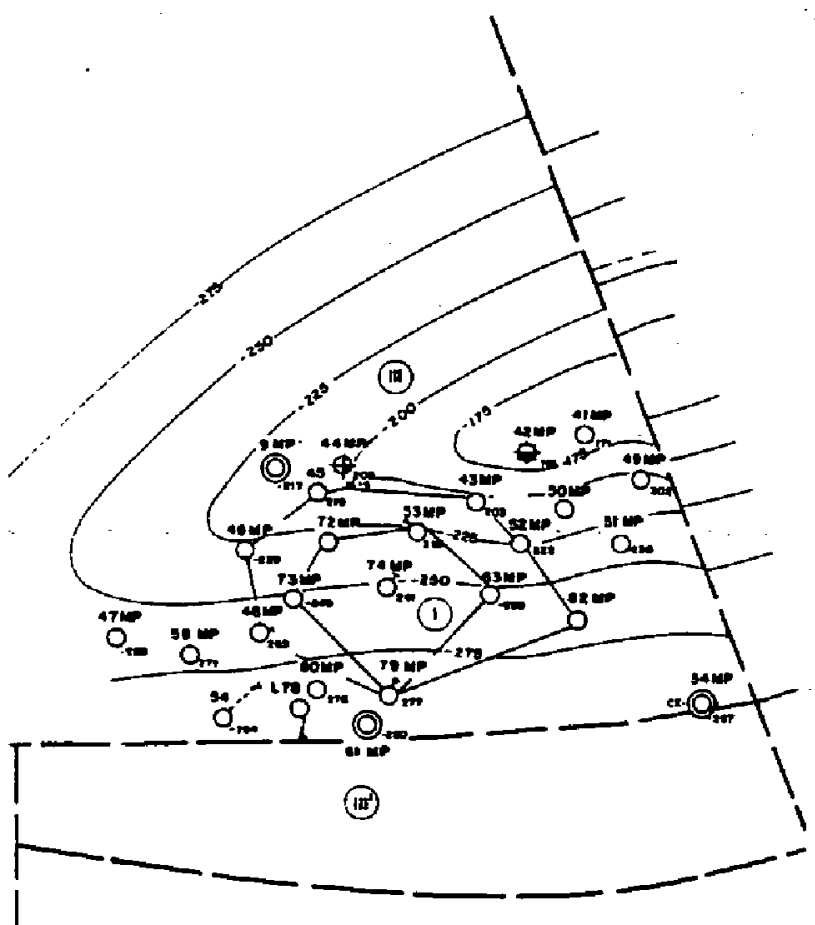

Fig. 1 - TEST PATTERN

The technical condition of well 74MP is as follows:

- casing: $51 / 2$ diameter, up to $773 \mathrm{~m}(2536 \mathrm{ft})$

- intermediate casing: $95 / 8$ in diameter

- surface casing: $133 / 8$ diameter up to $148 \mathrm{~m}$ (485 ft)

- perforated interval: 748 - $745 \mathrm{~m} \mathrm{(2454-2444 \textrm {ft } )}$

- the well was brought in in April 1987.

\section{LABORATORY INVESTIGATIONS}

Laboratory investigations were meant at:
- injection water treatment;

- properties of produced fluids:

- evaluation of the influence of added surfactants.

\subsection{INJECTION WATER CONDITIONING}

An experiment is being carried out on the Sotânga reservoir, consisting of conventional injection of purified reservoir water from a plant with a capacity of

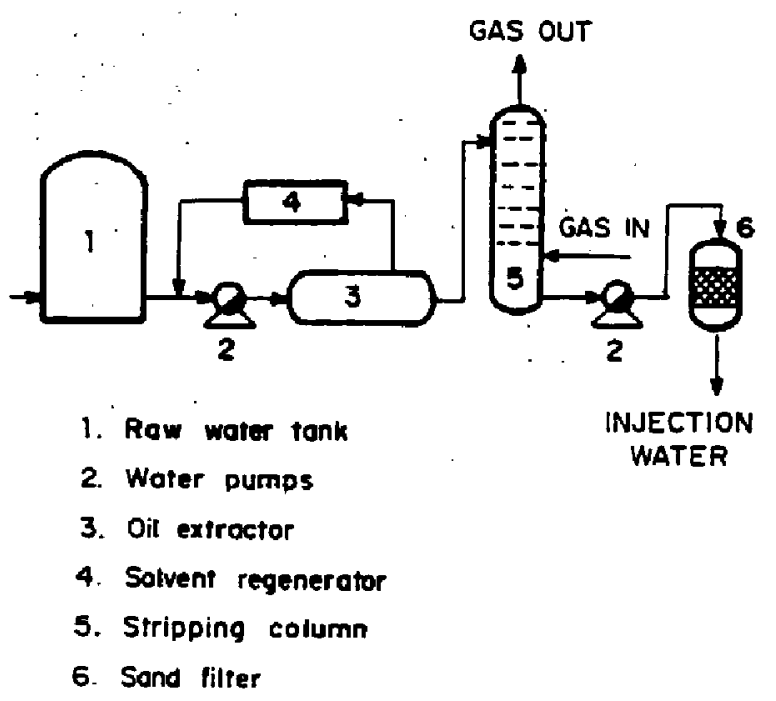

Fig. 2 - BLOCK DIAGRAM OF WATER CLARIFICATION PLANT

$2 \times 2000 \mathrm{~m}^{3} / \mathrm{d}$, and comprising the following steps:

- settling;

- oil extraction from water using a light solvent;

- removal of solvent traces and dissolved gases $\left(\mathrm{CO}_{2}\right.$ and $\mathrm{O}_{2}$ ) by natural gas stripping;

- quartz sand filtering [5].

The plant was operated during the period 1980-1985 to purify formation water, necessary for polymer solution injection, on Drăgäiești field.

The btock diagram of the plant is shown in Fig. 2.

Currently the gas stripping stage has been discontinued and purified water is conventionally injected and no corrosion and scaling difficulties are being encountered. Injection water and reservoir water characteristics are shown in Table 1

Table 1

\section{INJECTION WATER AND PRODUCED WATER CHARACTERISTICS}

$\begin{array}{lccc}\text { Characteristics } & \text { MU } & \text { Inj. Water } & \text { Prod.Water } \\ \text { Density } & \mathrm{kg} / \mathrm{m}^{3} & 1,098 & 1,090 \\ \text { pH } & & 6.10 & 6.6 \\ \text { Hydrocarbons } & \text { p.p.m. } & 4 & 108.5 \\ \text { Sediments } & \text { p.p.m. } & 33 & 63\end{array}$


Chemical Composition p.p.m.

Inj. Water

Prod. Water

$\mathrm{Na}$

$\mathrm{Ca}$

$\begin{array}{rr}53,770 & 39,848 \\ 3,741 & 2,918 \\ 1,513 & 1,492 \\ 93,365 & 70,645 \\ 151 & 10 \\ 549 & 515 \\ 85 & 67 \\ 3 & - \\ 153,177 & 115,495\end{array}$

Sediments represent iron salts which settle rapidly. Following sediments removal the waters are compatible.

Heating promotes the increase of the corrosion rate and of the scale formation $[9,10]$ which was confirmed by laboratory tests. Sediments built up by heating are not adherent and have a high iron content.

Physical-chemical treatments were tested in the laboratory to reduce the corrosion rate and the scale deposits within the experimental plant. The effectiveness of the treatment was evaluated by determining the corrosion rate and $\mathrm{Fe}_{2} \mathrm{O}_{3}$ content at a temperature of $90^{\circ} \mathrm{C}$ and at atmospheric pressure, for the treated water, as compared to the same type of determination at $20^{\circ} \mathrm{C}$ and atmospheric pressure for untreated water.

The comparative results for corrosion rate and indices are shown in Figure 3.

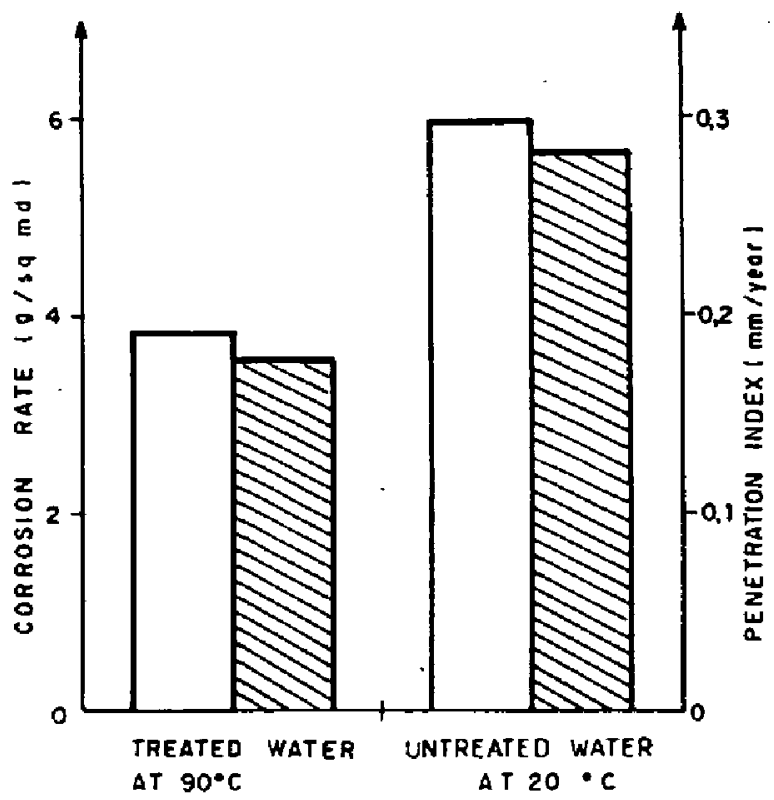

Fig. 3 - COROSION RATE AND
INDEX FOR TREATED
AND UNTREATED WATER

The reduction of the $\mathrm{Fe}_{2} \mathrm{O}_{3}$ content in the water reduces the tendency for scale deposits. The treatment results are represented graphically in Fig.4.
These results are deemed satisfactory and will be checked under static laboratory conditions at the pressure and temperature of the experimental plant $(0.6 \mathrm{MPa}$ and $150^{\circ} \mathrm{C}$ ). The device manufactured for this testing is shown in Figure 5.

The results will also be tested under dynamic conditions within the experimental plant by means of a device installed in the plant.

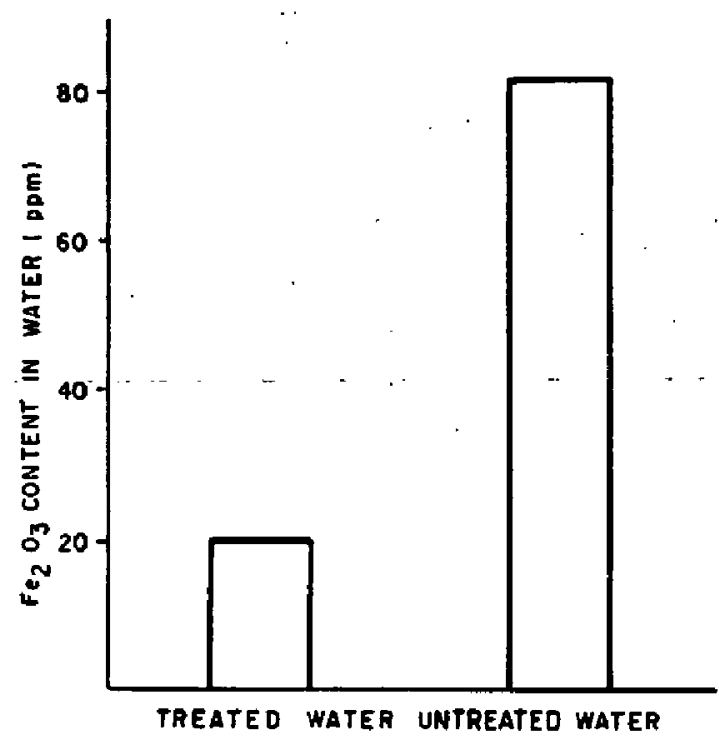

Fig. 4 - $\mathrm{Fe}_{2} \mathrm{O}_{3}$ CONTENT IN TREATED AND UNTREATED WATER

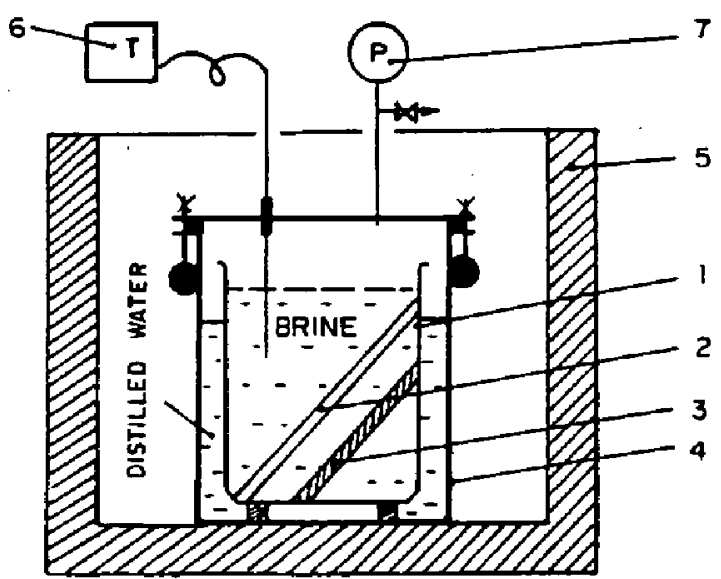

1. Removabte glass conteiner

2. Glass slide

3. Stell slide

4. Pressure container

5. Electric oven

6. Termocouple

7. Manometer 


\subsection{PRODUCED FLUIDS CHARACTERISTICS}

The main characteristics of the produced water were shown in Table 1. Gas composition is shown in Table 2.

Table 2

\section{Produced Gas Composition}

$\begin{array}{lc}\text { Components } & \text { \% vol. } \\ \text { CO } & 0.33 \\ \text { Methane } & 97.81 \\ \text { Ethane } & 1.41 \\ \text { Propane } & 0.22 \\ \text { Butane (i) } & 0.04 \\ \text { Butane (n) } & 0.06 \\ \text { Pentane (i) } & 0.03 \\ \text { Pentane (n) } & 0.02 \\ \text { Hexane } & 0.03 \\ \text { Heptane+ } & 0.05 \\ & \\ \text { TOTAL } & 100.00 \\ & \\ \text { The main characteristics of net oil are the following: } \\ \quad \text { - density at } 20^{\circ} \mathrm{C}: 923 \mathrm{~kg} / \mathrm{m}^{3}\left(21.5^{\circ} \mathrm{API}\right) \\ \quad \text { - pour point: }-21^{\circ} \mathrm{C} \\ \quad \text { - initial boiling point: } 170^{\circ} \mathrm{C} \\ \quad \text { - molecular weight: } 380 .\end{array}$

Figure 6 shows the oil kinematic viscosity variation with temperature.

Figure 7 shows the oil volume factor variation with temperature.

It is mentioned that the determinations for the viscosity and volume factor variation were made using clean oil (free of dissolved gas).

\subsection{EVALUATION OF SURFACTANTS ADDITION}

Hot water flooding diminishes insignificantly the oil/ water interfacial tension [1].

Laboratory investigations carried out in Canada [11] have shown that addition of sodium hydroxide or carbon dioxide to hot water increases oil recovery at temperatures around $100^{\circ} \mathrm{C}$ under reservoir conditions.

Currently, there is no carbon dioxide available at site. while the high mineralization of injection water renders inappropriate the use of sodium hydroxide which precipitates in contact with the injection water.

Various surfactants for reduction of oil/injection water interfacial tension were tested. Determinations were made at $30,40,50$ and $60^{\circ} \mathrm{C}$.

The best results were obtained using an ethoxylated block-copolymer [12.13] under current manufacture in Romania. This surfactant reduces the interfacial tension by about 40 times (from $42 \mathrm{mN} / \mathrm{m}$ to $1.1 \mathrm{mN} / \mathrm{m}$ ) with and optimal dose of $500 \mathrm{ppm}$ at a minimum temperature of $40^{\circ} \mathrm{C}$.

Displacement tests were carried out using an artificial core made of $0.3 \mathrm{~mm}$ diameter glass balls set inside a thermostated metal tube, with a length of $5 \mathrm{~m}$.

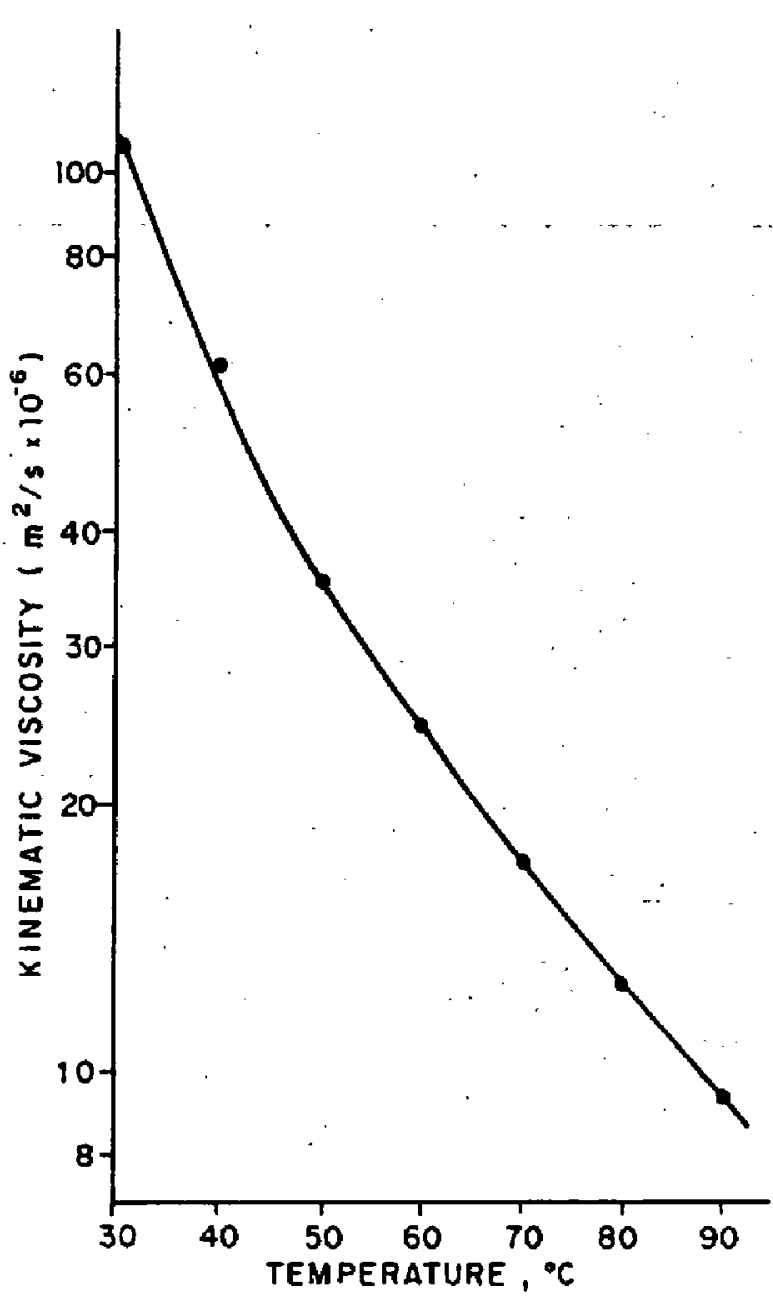

\section{Fig.6-VISCOSITY VARIATION WITH TEMPERATURE}

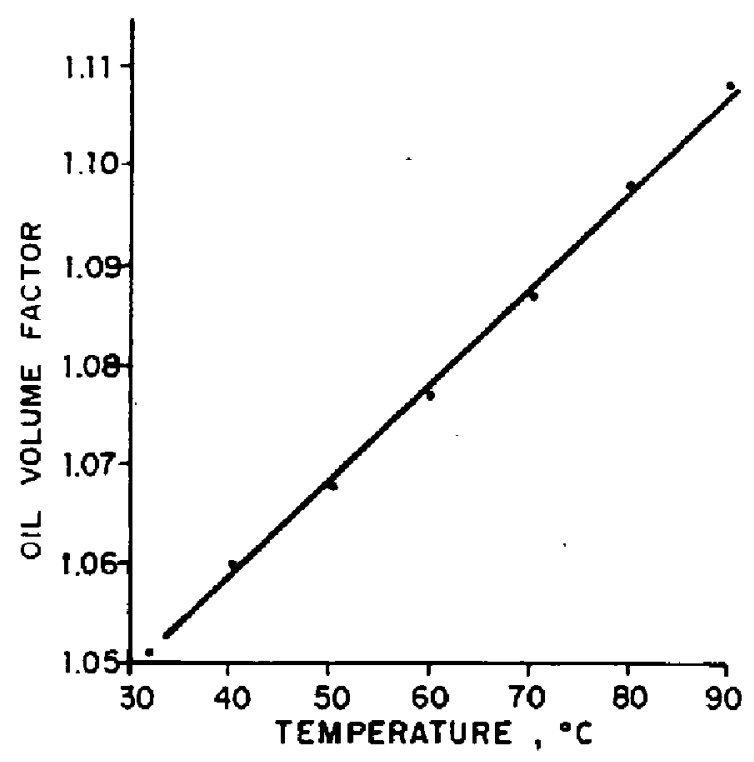

Fig. 7 - OIL VOLUME FACTOR VERSUS TEMPERATURE 
The cores were saturated with reservoir water and then with oil. Cores porosity was about $23 \%$ and cores permeability of about $18 \mu \mathrm{m}^{2}(18 \mathrm{D})$.

Determinations were made using injection water and injection water with $400 \mathrm{ppm}$ additives. The injected vater volume was about 3 pore volumes.

Figure 8 shows the comparative determinations results.

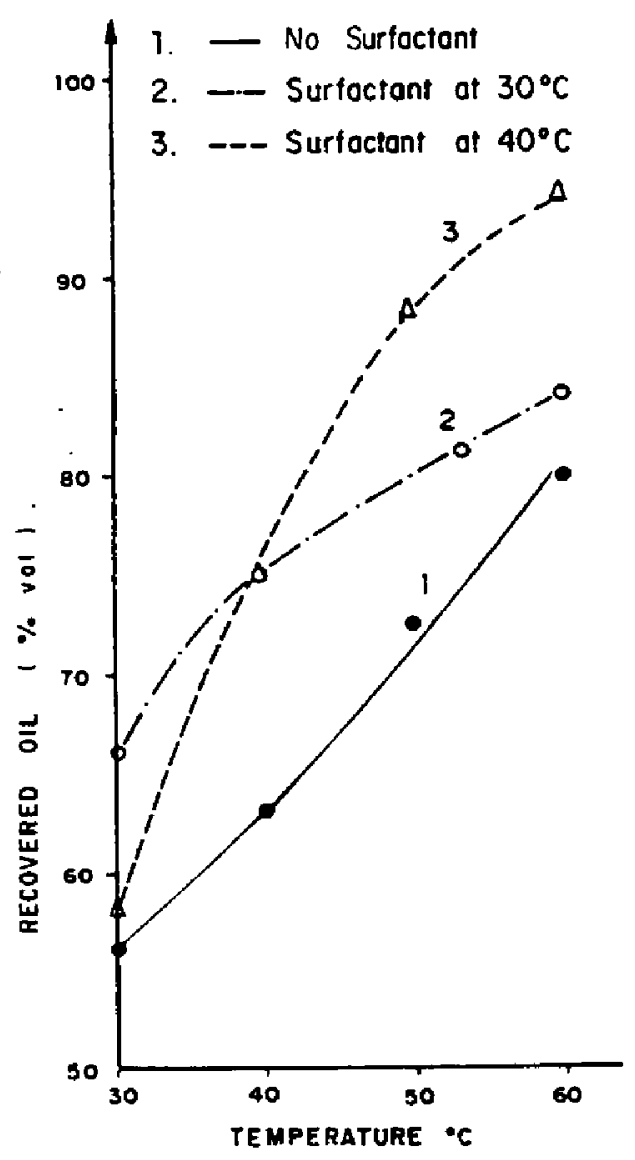

Fig. 8 - SURFACTANT EFFICIENCY
EVALUATION

Figure 8 illustrates the positive effect of addition of a dose of $500 \mathrm{ppm}$ surfactant at a temperature of $40^{\circ} \mathrm{C}$.

\section{PRELIMINARY MATHEMATICAL MODELING OF THE PROCESS}

In order to evaluate heat losses and the temperature distribution in the formation a mathematical model was prepared based on the extension of Marx and Langenheim [14] results by Lauverier [15] in a linear system. and by Malafeev [16] in a radial system.

Calculated temperatures for a plane radial model based on time and distance from the injection well are shown in Fig. 9.

Pretiminary calculations performed using this mathematical model show that after about 2 years of continuous injection, heat losses in the injection well and in the layers adjacent to the productive formation will surpass $70 \%$ of input heat.

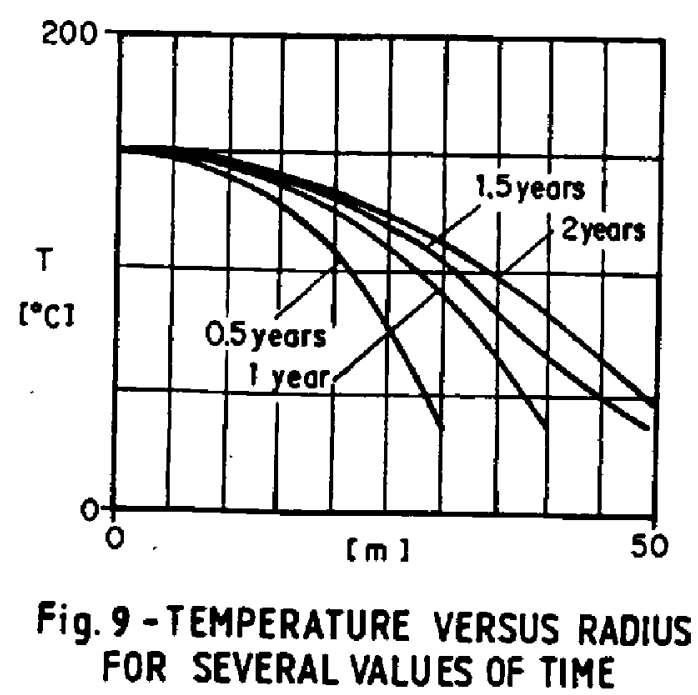

The analytical method of evaluation of hot waterflooding is being assessed.

\section{THE PROCESS}

For designing the process. the specific site conditions and the own experience in heating systems operation were taken into account using high efficiency heating equipments. These systems and equipments are used for heating crude oils with a high water content $(70 \%$ vol. to $90 \%$ vol.).

The experimental plant will be located neur the injection well and will have a nominal capacity of $60 \mathrm{~m}^{3} / \mathrm{d}$ and a maximum capacity of $120 \mathrm{~m}^{3} / \mathrm{d}$.

\subsection{HEATING SYSTEM}

A vertical metal heater will be used for injection water heating. Its main characteristics are shown in Figure 10. During the last five years, vertical metal heaters [6] have been used within a crude heavy oil heating system $[7,8]$ by overheating produced water.

Application of these systems and equipments to the experimental plant will entail a considerable cost reduction owing to the following reasons:

- no investments or operating costs are necessary for supply with fresh water from natural sources;

- no investments or operating costs are necessary for the current facilities and processes of advanced conditioning of produced water to be used for feeding the plant [9, 17];

- vertical metal heaters are not expensive. have a high thermal output and necessitate a reduced ground area for installation.

Hot water injection is, of course, an improved oil recovery process. Commercial application of such a process depends greatly on the facilities and equipments used for heating and water injection. Investments and operating costs associated with the use of the equipment and plant presented in this paper, which are sensibly lower 


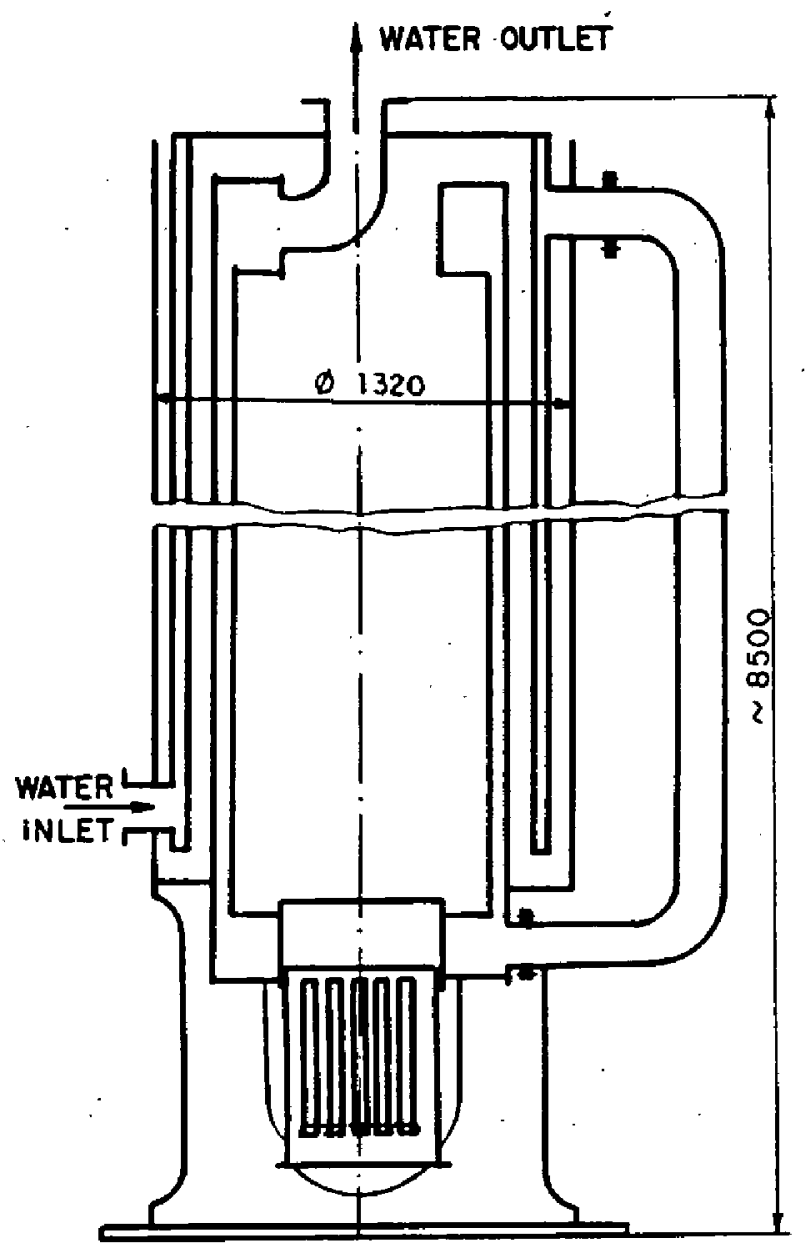

Working pressure : $0.6 \mathrm{MPa}$

Moximum temperafure : $160^{\circ} \mathrm{C}$

Heoting copocity : $7.10 \mathrm{Kj} / \mathrm{h}$

Thermol rendment: 0.92

\section{Fig. 10-VERTICAL HEATER}

than the current costs related to hot water injection. will contribute their share to increase the chances for applicability of hot water flooding.

Iniection water will be heated in a closed system within the experimental plant, to $150^{\circ} \mathrm{C}$, at a pressure of $0.6 \mathrm{MPa}$.

\subsection{Flow Sheet}

The process was designed in a closed system with a feeding stage at low pressure, with a heating stage, and an injection stage at high pressure.

The experimental plant block diagram is shown in Figure 11.

The water tank (1) is fed with purified water, which is pumped (2) at a pressure of about $0.6 \mathrm{MPa}$. through a certical heater (3) where it is heated to about $150^{\circ} \mathrm{C}$, and injected (4) at a pressure of about $2 \mathrm{MPa}$, into the injection well (5).

The plant is provided with back pressure regulators which maintain constant pressures in the process stages. Excess of hot water will be recirculated into the water

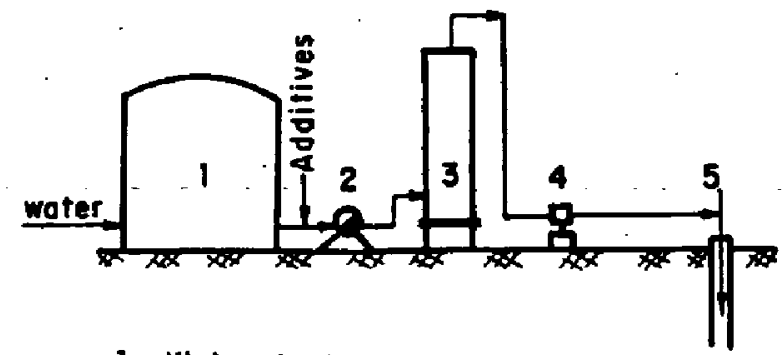

1. Water lonk

2. Water pumps

3. Vertical heater

4. Injection pumps

5. Injection well

\section{Fig. 11-BLOCK DIAGRAM OF EXPERIMENTAL PLANT}

tank (1) through a system precluding water vaporisation. To complete the experiment's data. the following devices will be mounted in the plant:

- backwashing metallic cartridge filter;

- device for testing corrosion rate and scale deposits in the process;

-device for testing the effectiveness of various thermal insulations on injection wells for hot fluids.

The thermal insulation on the injection well will be achieved by altering the ratio of the tubing/casing surfaces and by feeding heavy clean oil (with the initial boiling point temperature over $200^{\circ} \mathrm{C}$ ) within the annulus of the injection well.

Movable skids were designed for the water pumps and the injection pumps which facilitate mounting/dismantling and transportation operations for the experimental plant.

It should be mentioned that the skid of the injection pumps is equipped with outlet fittings with a nominal working pressure of $10 \mathrm{MPa}$, which ailows for extension of the applicability field to other reservoirs.

\section{CONCLUSIONS}

1. The plant offers possibilities for extension of hot water injection to enhance oil recovery providing cost reductions related to investments and operation of about 3 times less as compared to the current facilities used for hot fluids injection, while avoiding at the same time fresh water consumption from natural sources.

2. Laboratory investigations constitute the background for an effective treatment in order to reduce corrosion and scales deposits. and for increasing the efficiency of the process by adding surfactants to the injection water. 3. The process consists in heating the produced water to $150{ }^{\circ} \mathrm{C}$, in a closed system, at a pressure of $0.6 \mathrm{MPa}$, and its injection at a pressure up to $10 \mathrm{MPa}$.

4. The plant is made of transportable skids which facilitate its installation near the injection well and its transfer to other wells following completion of the experiment. 
5. The experimental plant for hot water injection will be fed with purified formation water and will be tested in an experimental pattern made up of an injection well and five output wells, on a reservoir located at a depth

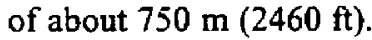

\section{REFERENCES}

1. P. DIA, M. COMBAROUS - Les methodes thermiques generales et l'injection des fluides chauds dans l'exploitation des gisements d'hydrocarbure - Institut Francais du Petrole, Edition Technip - Paris 1974, pp. 179-198.

2. IV.L. MARTIN, J. N. DEW, M.L. POWERS, H.B. STEVENS - Results of a Tertiary Hot Waterflood in a Thin Sand Reservoir. J.P.T. vol. 20. No. 8, July 1968, pp. 739-750.

3. A.CARCOANA, G. ALDEA - Increasing Ultimate Oil Recovery, Ed. Tehnică București, 1974, pp. 308-309 (in Romanian).

4. GUNTIS MORITA - E.O.R. Increase $24 \%$ Worldwide Claims $10 \%$ of U.S. Production. O.G.J.J. Special April 20, 1992, pp. 51-79.

5. V.V. POPP, N. SANCU, I.M. CUCULAT, G. DUMITRESCU - Process and Plant for Residual Water Conditioning - Romanian Patent 74.362/1978 (in Romanian).

6. V.D. DINULESCU - Boiler for Heating Oil on the Oilfields - Romanian Patent 59.461/1972 (in Romanian).

7. V.V. POPP. V.D. DNULESCU, D. TARBOIU; V. PORDEA - Procedure land Facility for Treating Medium and Heavy Oils - Romanian Patent 10 6741/1994 (in Romanian).

8. V.V. POPP. V.D. DINULESCU - Dehydration and Desalting of Heavy and Viscous Cnide Oil Produced by In-Situ Combustion - SPE 28539. SPE Annual Technical Conference. Sept. 25-28, 1994. New Orleans.

9. B.L. CARLBERG, B.M. CASAD, R.L. BRACE. F.B. CHAMBERS - Stabilize Water for High Temperature Flooding - O.G.J. July 2. 1962 pp. 120-122.

10. J.E. ODDO. M.B. TOMSON - Why Scale Forms and How To Predict It - SPE Production \& Facilities, Febrụary, 1994, pp. 47-54.

11. T.N. NASR, D.M. NGUYEN. A.S. McKAY - Hot Water Injection with Sodium Hydroxide or
Carbon Dioxide for the Recovery of Bitumen from Athabaska Oil Sands. The Fourth UNITAR/UNDI Int. Conf. Edmonton. Alberta, Canada, 7-12, Aug. 1988.

12. F. POPESCU, R, GOBJILA, T, BASARABESCU Composition for Control of Oil Emulsions and for Stimulation of Oil and Gas Producing Well. Romanian Patent $5 ! 410 / 1968$ (in Romanian).

13. F. POPESCU, T. BASARABESCU - Procedure for Preparing Oil Emulsions Control Agents. Romanian Patent 53831/1971 (in Romanian).

14. J.W. MARX, R.H. LANGENHEIM - Reservoir Heating by Hot Fluid Injection. Trans AIME (1959), vol. 216. PP. 312-315.

15. H.A. LAUVERIER - The Transport of Heat in an Oil Layer Caused by Injection of Hot Fluid Applied Scientific Research (1955) A5, pp. 145-150.

16. G.E. MALAFEEV - Calculation of the Temperature Distribution in a Formation when Pumping Hot Fluid into a Well - Neft i Gaz (1960) 3. No. 7. pp.59-64.

17. S.A. ZAIDI, K.M. SIMMS, S.E. KOK - Status of Produced Water in Westem Canada - Joint Cunada/Romania Heavy Otl Symposium. Sinaia- Romania, March 7-13. 